\title{
WHEN VIOLENCE MANUFACTURES MORE VIOLENCE: MAPPING THE EXPERIENCES OF WOMEN SURVIVORS OF INTERPERSONAL- VIOLENCE FROM URBAN INDIA
}

\author{
Ahalya Ganesh \\ Tata Institute of Social Sciences, Hyderabad, India
}

\begin{abstract}
Based on research using in-depth interviews with four women survivors of interpersonal violence from urban India, this study attempts to understand three key aspects of interpersonal violence against women. The first objective is to understand how survivors define and interpret the meaning of the term 'violence'. The second objective is to locate the question of gender into the study of interpersonal violence in India. The final objective is to analyse how institutions around survivors that are posited as being a refuge for them respond to their experience of violence. The findings of the study point to a dismal reality wherein the aforementioned institutions don't only prove ineffective in helping the survivor cope with their experience of violence, but also inflict more violence upon them due to the existing norm of patriarchal social culture.
\end{abstract}

Keywords: interpersonal violence; survivors; gender; patriarchy

\section{Introduction}

While considering the very nature of violence, it is integral that the question of power is raised. Whether it is in intimate-partner violence or structural violence that one considers to be violence, power is that without which violence cannot make itself known or viable. To understand the nature of violence, then, it becomes imperative that one begins with an evaluation both of the power relations piggybacking on the social structure that surround the stakeholders of violence and of the dynamics of power between the two or more stakeholders in the act of violence. While trying to contextualise a phenomenon like gender-based violence in a country like India, patriarchy becomes of grave significance. It brings with itself a power hierarchy that is embedded not just into the socio-political and economic institutions, but also into the psyche of each individual situated within the social system such that any transgression from the patriarchal norm warrants penalty. It is in this context that feminist scholarship recognizes that "women are discriminated against because of their gender" (Beirne and Messerschmidt, 1991), and deems, thus, that the personal must be politicised. In a system where 'action' is prized as belonging to the 'cult of masculinity' (Goffman, 1977) and inaction, consisting of virginity, restraint and modesty among others, is, by default, thrust upon women, the question of how docile must women be made in order to not be 'deserving' of the violence takes centre stage. Another object of investigation that then emerges is also about how gender-based violence is socially sanctioned.

Scholarship from other schools of thought, especially Foucauldian work would explain patriarchal social relations as a system of Power where the term 'power' itself is debunked of the negative connotations it is attached to and is understood as being coterminous with social change; implying fundamentally that power is anything that brings a certain modification to another's behaviour. Seen from this angle, one could extrapolate that resistance too, in the same sense, isn't an antonym to power but in fact, co-exists with it, not as an opposite ontological entity, but as one different from it, and in its magnitude lesser powerful than Power. (Heller, 1996) Integrating these two strands of thought, one could say that women are discriminated against, but they are not passive subjects upon whom violence is precipitated, but that they possess a "power, (in the Foucauldian sense) agency and resistance to struggle against this inequality" The act of speaking about oppression, especially when 
that speech stems from a personal experience of violence and oppression is always an act of resistance not only directly, but also symbolically against the structure or the individual oppressor

In any given social context in India, collectivistic culture occupies a prominent position. What that implies is that an individual - their rights, goals, needs, et cetera - is subjugated under that of a group. In such a case, the values prescribed to the society by patriarchy cannot be overridden merely by the claim for the individual rights of cis-women and trans- and other gendered people. Viewing and attempting to understand interpersonal violence against women against this backdrop then, leads one to cite the oft-repeated rhetoric that the system must be changed in order to affect any real change in the situation of women.

This paper examines how violence, and by extension, power operates in the patriarchal social system. This is done through observing everyday life practices and analysing through them, how power and agency operate in mundane situations and how women engage with those social power structures in different ways (Bourdieu, 1977). Another fundamental question that this paper will address is whether the gender of the two or more individuals party to the interpersonal violence must be considered pertinent. The final argument that the paper will attempt to make is on how bystanders who, themselves are actors in the various social institutions that surround the survivor, contribute to the interpersonal violence experienced by the survivor during the latter's future interaction with said institutions.

\section{Method}

For the purpose of finding comprehensive answers to all of the research questions, the author used primary method of data collection. The research design comprised of semi-structured interviews conducted over the span of two months with four women survivors of violence.

Convenience non-probabilistic sampling was done using the Snowball method. The variables amongst the sample that were homogenous were the location of the women, and to some extent, their class position. The upbringing and residence of all of the four women was in an urban South Indian environment. Each of them studied in a school whose curriculum was taught in the medium of English. Since English-medium schools are accessible only to people of the middle and upper classes, one can also infer that these women belong to the aforementioned classes.

For the purpose of the investigation, some definitional constraints were put in place. The term 'violence' was taken to mean any and all forms of interpersonal violence. Other types of violence such as structural or institutional violence are excluded for reasons of clarity. The term 'violence' throughout the course of interviews was taken by the interviewer as an empty concept ${ }^{1}$ so as to ensure that the operational definition used isn't one that excludes the experiences of the participant or hinders with what is understood as violence by the survivors.

\section{Results and Discussion}

Even though knowledge isn't grounded simply in that which is opined and said to be experience, women's experiences and what women say, especially from the vantage point of a survivor of violence, can contribute significantly to the creation of knowledge about violence (Harding, 1992). The first and perhaps most fundamental answer that was sought by the author is what the survivor deemed to be violence. Although most of the answers to an open-ended question probing into the same followed a common pattern whereby a typology

\footnotetext{
${ }^{1}$ An empty concept (Frege, n.d.) is one that has an unintelligible or incomplete definition. The concept then remains empty for as long as it fails to encompass all its constituent parts.
} 
was given to the author such that it classified interpersonal violence into distinct categories of Physical (including Sexual), Verbal and Psychological Violence, during the course of the interviews greater nuances were revealed. Taking those nuances into consideration, violence according to the participants in this study can be defined as something that "can be visible, invisible, camouflaged in moral terms, but the underlying power is the threat of penalties, of coercive power, of increasing the vulnerability of the victim in many subtle ways that deny options or autonomy for her own being" (Krishnaraj, 2007).

For the purpose of analysis, the author will posit the types of violence inflicted on the survivors as being of two types - 'violent' violence and 'subliminal' violence. Violent violence, as used by the author here, refers to an act of violence where the individual perpetrator's intention was to affect harm upon the survivor and subliminal violence refers to acts of violence where the individual perpetrator sees perhaps no harm done in their act, as evidenced by their future interactions with the survivor. Note here that the distinction made between the types isn't reflective of the magnitude or the validity of the violence that had been precipitated but of the acknowledgement of violence by the perpetrator and the social actors that the author deems to be bystanders in the violent exchanges where the survivor was victimised. This categorisation will help in contextualising the responses of the bystanders (defined later in the paper) to their finding out about the violence faced by the survivor.

It is also important to note that the categorisation into Violent and Subliminal violence is based on the survivors' future interactions with the perpetrator(s) themselves and how the episode(s) of violence had changed (or not changed) those interactions.

\section{Violent Violence}

This type of violence is the most explicit expression of the hierarchy between the perpetrator and the survivor; this hierarchy is also furthered through this type of act of violence.

For Sangeetha" who grew up in a house that in her words "never had any peace", violence was nothing new. She often bore witness to her mother getting beaten by her father for things as mundane as the food not having enough salt in it, for his colleagues' not answering their phones et cetera. The beatings were often so extreme that Sangeetha grew up believing that this is the norm in every household. Her first experience with violence where she was victimised, however, was not of the type of physical violence that she was most exposed to, but of verbal and psychological violence at the hands of her father. She was under a constant threat of violence with her father threatening to stop her schooling - her only respite from her turbulent family life and the one thing she claims she's always expressed love for-to get her and her mother to comply with his demands of them. Her subsequent experiences with violence were at the hands of her male relatives (uncles and cousins) who made multiple attempts to impose themselves on her sexually. What is categorically different about the abuse that was attempted on her by her uncles and cousins, and her father was her silence about the former even to her closest kith and kin and the fact that the latter's abusive nature was an open secret to all in the extended family network.

For Subiksha* whose exposure to and direct experience of violence began after she moved into her nuptial home. She was subjected to the full spectra of violence ranging from physical and sexual to psychological, verbal and symbolic violence. Other than facing severe physical abuse almost every day, she had to endure years of verbal abuse when her husband questioned her whereabouts and accused her of infidelity and of being a prostitute, stemming from what can be inferred as her his sexual jealousy. Perhaps the violence she faced was amplified and the perpetrator was granted impunity due to the shared patrilocal residence in which Subiksha, her husband, their children and her in-laws lived where his position of authority wasn't to be questioned or

\footnotetext{
${ }^{*}$ The names have been changed in order to maintain anonymity and confidentiality
} 
challenged. ${ }^{2}$ Other kinds of violence precipitated on her included psychological violence wherein she was denied material goods of her choice and her expression of desire for them was purported to be the reason for her being physically abused. She was once also exiled to her natal home along with her three children under the pretext of a vacation but was later disallowed from coming back home without bringing more money as dowry. She was also told that she was no longer welcome in her nuptial home as her husband was to remarry owing to "her inadequacy" and that of her family. The same could also be termed the reason for Subiksha's husband's act of making an attempt on her life by pouring water into the kerosene that she was going to use for cooking in the anticipation that she will set herself ablaze. In her accounts regarding sexual victimisation, Subiksha also recalled how besides being assaulted by her husband (which is not termed abuse by either her society or the law of the land), one of his brothers also tried to impose himself on her. This instance was something that she kept hidden by her own volition, for fear of vilification of the perpetrator. Her recounting of the violence she endured at the hands of her (now, former) husband is, however, an act of resistance against the vow of silence she was made to take by him and his family.

Kriti $^{*}$, a survivor of severe child sexual abuse, physical assault and psychological trauma at the hands of her peers and seniors at school was targeted on two counts, the foremost being her gender expression as a transwoman and the second being her parents' unequal status with that of the survivors'. She was subjected to coercive penetration, denuding and other heinous acts couched in the pretext of 'ragging' by her male seniors in the school hostel during her pre-adolescent years and she was told that should she speak of the violence to anybody, her parents will be humiliated and maimed physically by them. She even recounted that because her abusers' parents occupied high ranks in the government of the states and the union of India and enjoyed the privileges that came with them at her school, she saw how very plausible it was that her speaking up at the time would result in peril for her family and herself.

\section{Subliminal Violence}

This type of violence, as defined by the author previously, refers to violence that causes unintended harm ${ }^{3}$ on the survivor while the perpetrator enjoys the privilege of not requiring even impunity, as the cultural norms and habits around them and by extension, they, do not acknowledge their personal offence against the survivor as being a transgression.

Zara*, another survivor of child sexual abuse, told a very different story of abuse than Kriti. Her experience was located within the closed doors of her aunt's house outside of her home city and the perpetrator of the violence that was inflicted on her at age 6, was her adolescent male cousin. However, in her case, the abuser made no attempt to "conceal that there was anything abnormal about the actions he took against" her.

As a child, Sangeetha also faced subliminal violence at the hands of her father. As the patriarch, he decided exactly what everyone wore, ate and how they carried on their day-to-day activities and any flouting of norms entailed punishment. Sangeetha was forced to walk the tight rope that ensured that she fell to neither end of the continuum where both extremes were that she desecrates the impression of her belonging to a decent family. So, while she had to adorn herself with jewellery and expensive clothing when meeting her father's colleagues and friends, at all other times she had to be in attire that she openly decried as being mismatched and unflattering just so that she doesn't attract 'unwanted attention from men' and besmirch the family name. She felt that her person had been overly sexualised by the man who, under the guise of protecting her, never trusted her.

\footnotetext{
${ }^{2}$ See Quinsey, 1984 for more work on patrilocality and its impact on violence

${ }^{3}$ See also Peter Lawler's A Question of Values: Johan Galtung's Peace Research (1995: 82-83) for more work on unintended (structural) violence.
} 
However, she also felt that non-compliance on her part would result in violence against her mother, which in her words was a reality too plausible to be dismissed for the sake of her personal freedom.

On Subiksha, subliminal violence was precipitated by her mother, who constantly blamed her for her being ousted from her nuptial home and imposing spinsterhood on her younger sisters.

\section{Bystanders and Future Interactions}

In this section, the author shall analyse how bystanders who find out about the violence endured by the survivors contribute to the violence itself and thus fail to be safe spaces for the survivor. A bystander is defined here, as any actor who holds membership in the institutions that surround the survivor.

For all four of the respondents, some form or other of violence, usually verbal and psychological, was precipitated by the bystanders in whom the survivor confided or those who found out through other sources about the episodes of violence the survivor had endured; thus invalidating the idea that in a collectivist culture, institutions, especially family are excellent resources for care-giving for those who require it. ${ }^{4}$

\section{Muting the Survivor}

Subiksha was, for reasons of maintaining a 'good' reputation for the family in society, muted by several actors, including her parents, from speaking about the domestic violence she endured. She was also reprimanded by many social actors when, after three decades of marriage and the domestic violence it entailed, her children aided her separation from her husband.

\section{Dismissing the experience}

As mentioned previously, many of the accounts of violence as endured by the survivors who partook in this research and those given by others were dismissed as being 'not violent enough' to form a part of the discourse on violence. Subiksha's experience with sexual assault ${ }^{5}$ and physical violence by her husband was considered too 'normal' by other women in her family in whom she confided, to be something from which she needed rescuing.

\section{Shaming the Survivor}

Sharing of violent experiences by the survivors becomes a counterproductive exercise when members of their family, blame them for the violence they had to endure. This is true not only for Subiksha, but also for Kriti, who, upon talking about getting bullied at school to her parents, was told that those instances of violence were inevitable if she 'walks and talks like a girl' as she did.

\section{Discounting the experience of violence}

For survivors like Zara, confiding in family members entailed their being incredulous of and subsequently being in denial about her experience. She was also asked to interact 'normally' with her abuser but 'stay careful' when she had to stay over in the same house as him. She had to take these steps as her experience was to be kept a

\footnotetext{
${ }_{5}^{4}$ See Chadda and Deb,2013 and, Pyke and Bengtson, 1996

${ }^{5}$ Sexual assault here includes rape. But for the reason that the legal definition of rape is a purely male-view of violence (MacKinnon, 2005) of a crime committed mostly on women, the author has chosen to not use it as part of the terminology in her research.
} 
secret from members of the extended family. Other bystanders who knew in part about the violence, because of their having witnessed some parts of it, treated it as though it were just a joke, causing further distress to the survivor.

Kriti had a similar experience with counselling centres which, though designated to help the survivors of violence, became violent in their own right by asking questions regarding how the survivors 'construct' the violence and thus insinuating that the survivors' experience may well be something that they fabricated.

\section{Conclusion}

Often in the discourse about gender-based inter-personal violence, the causes for violence are attributed to various dispositional characteristics of the perpetrator or to the deficiencies in the relationship between the perpetrator and the survivor; but the Feminist critique thereof has yielded alternate perspectives on the same and the attribution of the causes of violence has thus been accorded to the imbalance of power among the genders. This perspective argues that in the family, a woman is often treated 'as an adjunct, or instrument, of the needs of others, as a mere reproducer, cook, cleaner, sexual outlet, caretaker, rather than as a source of agency and worth in her own right' (Nussbaum, 2000) and thus, the violence precipitated on her isn't seen as one that hampers the social structure of the family and by extension, is not of consequence to the members of it.

In a collectivist patriarchal culture such as that of India, women's bodies often become the battleground upon which the war to usurp moral high-ground is fought. The moral uprightness of the family is seen as being determined by the chastity and virginity of the women in it, the task of guarding which becomes primary to its elder men. The success of patriarchy lies in its indoctrination into everybody's minds. The author believes that it is through this that women, whose traditional role is to socialise the young, also indulge in ensuring that the same conservative ideas that allow for their subjugation are kept sacrosanct by their young ones, lest they should be labelled 'bad' mothers and sisters.

The author would then like to conclude that perhaps the most important reason for there being such deafening silence around gender-based violence is that it is as integral in patriarchy to ensure that the power-imbalance among genders is maintained at all levels as it is in capitalism that there be economic stratification and division of labour.

\section{Acknowledgements}

The author would like to convey her most sincere gratitude firstly to Dr. Jessy K Philip for her comments and suggestions on the direction of research and for encouraging and yet, humbling the author every step of her way.

Gratitude is due also to Dr. U. Vindhya without whose advice and guidance, undertaking research would've been but a fantastic dream.

Finally, the author would like to thank wholeheartedly Ms. Afrin Shairaj and Mr. Haseeb PP for their honest feedback and criticisms on the author's work which focused and fine-tuned the direction that the paper has taken.

\section{References}

Beirne, P. and Knepper, P. (1991). Criminology. San Diego: Harcourt Brace Jovanovich.

Chadda, R. and Deb, K. (2013). Indian family systems, collectivistic society and psychotherapy. Indian Journal of Psychiatry, 55(6), p.299.

Goffman, E. (1977). The arrangement between the sexes. Theory and Society, 4(3), pp.301-331. 
Harding, S. (1992). After the Neutrality Ideal: Science, Politics, and Strong Objectivity. Social Research: An International Quarterly, 59(3).

Heller, K. (1996). Power, Subjectification and Resistance in Foucault. SubStance, 25(1), p.78.

Krishnaraj, M. (2007). Understanding Violence Against Women. Economic and Political Weekly, 42(44), pp.9091.

MacKinnon, C. (2005). Sex and Violence. In: J. Lorber, ed., Gender Inequality: Feminist Theory and Politics, 1st ed. Roxbury Publication, p.122.

Nussbaum, M. (2000). Women and human development. Cambridge: Cambridge University Press, p.243.

Pyke, K. and Bengtson, V. (1996). Caring More or Less: Individualistic and Collectivist Systems of Family Eldercare. Journal of Marriage and the Family, 58(2), p.379.

Quinsey, V. and Chaplin, T. (1984). Sexual Arousal to non-sexual violence and sadomasochistic themes among rapists and non-sex-offenders. Journal of Consulting and Clinical Psychology, 52, pp.651-657. 